\title{
Erratum: Campbell et al. 2018
}

In the article, Campbell, B. I., Aguilar, D., Conlin, L., Vargas, A., Schoenfeld, B., Corson, A., Gai, C., Best, S., Galvan, E., \& Couvillion, K. (2018). Effects of High Versus Low Protein Intake on Body Composition and Maximal Strength in Aspiring Female Physique Athletes Engaging in an 8-Week Resistance Training Program. International Journal of Sport Nutrition and Exercise Metabolism, 28(6), 580-585, https://doi.org/10.1123/ ijsnem.2017-0389, the acknowledgements did not indicate that author Brad J. Schoenfeld serves on the advisory board for Dymatize Nutrition. The online version of this article has been updated so that the acknowledgements include the following statement: B.J. Schoenfeld serves on the advisory board for Dymatize Nutrition. He was not involved in the data collection process for the study; his contribution was to help in the interpretation of findings and write-up of the manuscript. 